\title{
ĐẶC ĐIỂM HOẠT ĐộNG CỦA GIÓ MÙA MÙA HÈ TRÊN LÃNH THỔ VIÊT NAM
}

\author{
Chu Thị Thu Hường ${ }^{1}$, Trần Đình Linh ${ }^{1}$
}

Tóm tắt: Đặc điểm hoạt động của SM trên lãnh thổ Việt Nam đã được phân tích dựa trên sự biến đổi trong ngày bắt đầu, kết thúc, thời gian kéo dài và cuờng độ của nó. Tù bộ số liệu tái phân tích truò̀ng HGT và U tại mục 1000hPa, 850hPa lúc 7 giờ hàng ngày và trung bình tháng trong thời kỳ 1981-2015, các chỉ số SM trên hai miền khí hậu Việt Nam đã được xác định. Đồng thời, các chỉ số và chi tiêu SM trên tùng miền cũng được đưa ra nhằm loại bỏ đới gió tây nam tù ACTBD. Nhũng kết quả chỉ ra rằng, SM trên miền khí hậu phía Nam thuờng bắt đầu sớm và kết thúc muộn hơn so với miền khi hậu phía Bắc. Trong các năm El Nino, SM thuờng bắt đầu muộn và kết thúc sóm hơn trong các năm La Nina. Trong thời kỳ 1981-2015, trên cả hai miền, SM đều có xu thế đến sớm hơn khoảng 1 đến 2 ngày/thập kỷ. Ngược lại, ngày kết thúc SM trên miền khi hậu phía Nam lại có xu thế muộn hơn khoảng 3,2 ngày/thập kỷ, trên miền khi hậu phía Bắc thì biến đổi không nhiều. Do đó, thời gian hoạt động của SM có xu thế tăng khoảng 5,7 ngày/thập kỷ (ở miền khi hậu phía Nam) và 1,27 ngày/thập kỷ (ở miền khi hậu phía Bắc). Hơn nũa, cuờng độ của SM trên các vùng khí hậu phía Nam cũng mạnh hơn khoảng 2 lần so với các vùng khi hậu phía Bắc.

Từ khóa: Gió mùa mùa hè, chỉ số U850, miền khi hậu phía Bắc, miền khi hậu phía Nam.

Ban Biên tập nhận bài: 12/7/2019 Ngày phản biện xong: 20/8/2019 Ngày đăng bài: 25/09/2019

\section{1. Đặt vấn đề}

Như chúng ta đã biết, gió mùa mùa hè (SM) trên khu vực Đông Nam Á nói chung và ở Việt Nam nói riêng được thể hiện bởi đới gió tây nam từ các trung tâm phát gió ở Bán cầu Nam $(\mathrm{BCN})$ như Mascarene và áp cao Châu Úc hội tụ về rãnh gió mùa hay dải hội tụ nhiệt đới [4]. Cho đến nay, trên thế giới và ở Việt Nam, đã có rất nhiều các nghiên cứu về $\mathrm{SM}$, nhất là các nghiên cứu xác định ngày bắt đầu $\mathrm{SM}$ trên các khu vực. Đặc biệt, cũng có không ít các chỉ số SM được đưa ra nhằm xác định ngày bắt đầu và cường độ của $\mathrm{SM}$ trên mỗi vùng.

Cụ thể, trên khu vực phía Tây Nam Ân Độ, ngày bắt đầu $\mathrm{SM}$ thường xảy ra trong thời gian từ ngày $30 / 5$ đến $2 / 6$ [8]. Tuy nhiên, khi phân tích những biến đổi của vận tải ẩm trên khu vực trong thời kỳ 1948-2000, Fasulo và Webster (2003) [7] lại cho rằng, SM trên khu vực này bắt đầu trung bình vào ngày $4 / 6$ và kết thúc vào ngày

${ }^{1}$ Trưòng Đại học Tài nguyên và Môi trường HN Email: ctthuong@hunre.edu.vn
7/9 với độ lệch chuẩn (ĐLC) tương ứng là 7,4 và 11 ngày. Hơn nữa, khi sử dụng độ đứt gió thẳng đứng trung bình trong vùng $5^{\circ} \mathrm{N}-20^{\circ} \mathrm{N}, 40^{\circ} \mathrm{E}-$ $80^{\circ} \mathrm{E}$ trên mực $850 \mathrm{hPa}$ và $200 \mathrm{hPa}$ và dị thường nhiệt độ trung bình vùng $10^{\circ} \mathrm{N}-17.5^{\circ} \mathrm{N}, 65^{\circ} \mathrm{E}-$ $75^{\circ} \mathrm{E}$ để xác định ngày bắt đầu và kết thúc $\mathrm{SM}$ trên lãnh thổ Ấn Độ, Prasad và cs (2005) [12] cho rằng, ngày bắt đầu SM trong thời kỳ 19582001 dao động trong thời gian từ giữa tháng 5 đến giữa tháng 6 , còn ngày kết thúc $\mathrm{SM}$ thì từ khoảng cuối tháng 9 đến tháng 10 .

Khi phân tích cấu trúc không gian và biến đổi theo thời gian của hoàn lưu khí quyển trên bán đảo Đông Dương, Zhang và cs (2002) [14] cũng cho rằng, ngày bắt đầu $\mathrm{SM}$ trên khu vực Đông Dương trong thời kỳ 1951-1996 trung bình là ngày $9 / 5$ với độ lệch chuẩn là 12 ngày. Trên khu vực Biển Đông, khi sử dụng chỉ số gió vĩ hướng trung bình vùng $\left(5^{\circ} \mathrm{N}-15^{\circ} \mathrm{N}, 110^{\circ} \mathrm{E}-120^{\circ} \mathrm{E}\right)$ mực $850 \mathrm{hPa}$ (U850), Wang và cs (2004) [13] cho rằng, ngày bắt đầu $\mathrm{SM}$ trên khu vực Biển Đông trong thời kỳ 1948-2001 thường xảy ra vào pen- 
tad thứ 28 (từ ngày 15 đến 20/5). SM đến sớm nhất vào pentad thứ 25 (từ ngày 1 đến ngày 5 tháng 5) và muộn nhất vào pentad thứ 34 (từ ngày 14 đến ngày 19 tháng 6 ). Song khi sử dụng tốc độ thế mực $850 \mathrm{hPa}$ trung bình trong vùng $\left(0-10^{\circ} \mathrm{N}, 105-120^{\circ} \mathrm{E}\right)$, Peng Liu và cs (2009) [10] lại cho rằng, $\mathrm{SM}$ trên khu vực Biển Đông bắt đầu sớm hơn (sớm nhất vào pentad thứ 23 ) và kết thúc muộn hơn (muộn nhất vào pentad thứ 32) trong nghiên cứu của Wang và cs (2004). Tương tự như kết luận của Peng Liu và cs (2009) [10], khi sử dụng chỉ số U850 trên khu vực phía Nam biển Đông $\left(5-15^{\circ} \mathrm{N}, 110-120^{\circ} \mathrm{E}\right)$ để xác định ngày bắt đầu SM, Trần Quang Đức (2011) [1] cho rằng, trong thời kỳ 1950-2010, ngày bắt đầu của SM trên lãnh thổ Việt Nam ngày càng sớm hơn, mùa SM ngày càng dài hơn, nhưng cường độ của nó lại có xu hướng yếu đi. Bên cạnh đó, Kajikawa và Wang (2012) [9] cũng cho rằng, ngày bắt đầu SM trên khu vực Biển Đông trong thời kỳ 1994-2008 đến sớm hơn trong thời kỳ 1979-1993 khoảng 3 pentad, tương ứng là ngày $14 / 5$ và $30 / 5$.

Ngày bắt đầu SM trên các vùng khí hậu Việt Nam cũng đã được Dzung Nguyen-Le và cs (2014) [6] phân tích dựa trên số liệu gió, nhiệt, ẩm, mưa tại 54 trạm khí tượng và số liệu tái phân tích trong thời kỳ 1979 - 2003. Kết quả cho thấy rằng, ngày bắt đầu $\mathrm{SM}$ thường sớm nhất trên các khu vực miền núi Tây Bắc (khoảng ngày 25/4). Ở các vùng đồng bằng Bắc Bộ và Nam Bộ, $\mathrm{SM}$ thường bắt đầu vào giữa tháng 5 . Còn trên vùng ven biển Trung Bộ, do ảnh hưởng của địa hình, mùa $\mathrm{SM}$ được đặc trưng bởi hiện tượng gió phơn khô nóng và thường bắt đầu vào cuối tháng 5 . Ngày bắt đầu và cường độ SM trên lãnh thổ Việt Nam cũng được Nguyễn Đăng Mậu (2018) [3] xác định dựa trên chỉ số U850 trung bình vùng $\left(5^{\circ} \mathrm{N}-15^{\circ} \mathrm{N} ; 100^{\circ} \mathrm{E}-110^{\circ} \mathrm{E}\right)$. Khi đó, SM ở Việt Nam thường bắt đầu vào khoảng pentad thứ 27 (ngày 11/5) với độ lệch chuẩn khoảng 9,5 ngày và kết thúc vào khoảng pentad thứ 57 (ngày 08/10) với độ lệch chuẩn là 12 ngày. Khi kết hợp cả chỉ số U850 và chỉ số mưa, Ngô Thị Thanh Hương (2018) [2] cho rằng, ngày bắt đầu/kết thúc SM trên khu vực Tây Nguyên trung bình là ngày $13 / 5$ và $30 / 9$ với độ lệch chuẩn lần lượt là 17,8 ngày và 10,2 ngày và trên khu vực Nam Bộ, lần lượt là ngày $15 / 5$ và ngày $13 / 10$ với độ lệch chuẩn tương ứng là 14,1 ngày và 13,6 ngày. Đặc biệt, ngày bắt đầu SM trên cả hai khu vực thường có xu thế sớm hơn trong những năm gần đây.

Ngoài ra, hoạt động của SM trên khu vực Việt Nam cũng đã được phân tích dựa trên chỉ số U850 như Nguyễn Thị Hiền Thuận (2005) [5], Phạm Xuân Thành và cs (2010) [11],...). Các kết quả nghiên cứu cũng chỉ ra rằng, do ảnh hưởng của địa hình mà các đặc trưng của $\mathrm{SM}$ trên các vùng khí hậu Việt Nam sẽ khác nhau. Ngày bắt đầu SM trên các vùng khí hậu Việt Nam thường dao động từ cuối tháng 4 đến cuối tháng 5 . Tuy nhiên, theo Nguyễn Đức Ngữ và Nguyễn Trọng Hiệu (2002) [4], trong thời kỳ đầu mùa (tháng 4 và đầu tháng 5), đới gió tây nam trên lãnh thổ thường có nguồn gốc từ áp thấp Nam Á, đới gió tây ngoại nhiệt đới. Còn đới gió tây nam xuất phát từ các trung tâm áp cao $\mathrm{BCN}$ thường xuất hiện từ khoảng giữa tháng 5 và hoạt động mạnh trong thời kỳ chính hè (tháng 6,7 và 8 ). Thực tế, đới gió tây nam trong thời kỳ đầu mùa hè còn có thể bắt nguồn từ rìa phía Tây của áp cao cận nhiệt Bắc Thái Bình Dương (ACTBD) khi nó lấn sang phía Tây. Khi đó, ở từng vùng trên khu vực Việt Nam, gió tây nam vẫn xuất hiện nhưng lại không phải là gió tây nam xuất phát từ các áp cao Mascarene và áp cao châu Úc. Bởi vậy, nếu chỉ sử dụng chỉ tiêu U850 trung bình trên khu vực nào đó có giá trị lớn hơn hoặc bằng $0,5 \mathrm{~m} / \mathrm{s}$ để xác định ngày bắt đầu SM thì có thể sẽ chưa thực sự đúng với bản chất của SM. Hơn nữa, sử dụng một chỉ số để xác định các đặc trưng SM trên toàn lãnh thổ Việt Nam trong khi các đặc trưng đó ở phía bắc và phía nam lãnh thổ là khác nhau.

Chính vì vậy, nghiên cứu xác định ngày bắt đầu, kết thúc SM trên lãnh thổ Việt Nam dựa trên cơ sở đới gió tây nam trên khu vực chỉ bắt nguồn từ áp cao châu Úc và áp cao Mascarene sẽ là nội dung chính trong bài viết này.

\section{Số liệu và phương pháp nghiên cứu 2.1. Số liệu}


Số liệu được sư dụng trong bài viết này bao gồm số liệu ngày, trung bình tháng của trường độ cao địa thế vị (HGT), gió vĩ hướng (U) trên các mực đẳng áp $1000 \mathrm{mb}$ và $850 \mathrm{mb}$ trong thời kỳ 1981-2015. Số liệu được thu thập trên khu vực $-40^{\circ} \mathrm{S}-80^{\circ} \mathrm{N}, 30^{\circ} \mathrm{E}-160^{\circ} \mathrm{E}$ với độ phân giải là 0,25 độ kinh vĩ và được cung cấp bởi Trung tâm dự báo hạn vừa châu Âu (ERA), được tải về tại địa chì:

http://apps.ecmwf.int/datasets/data/interimfull-daily.

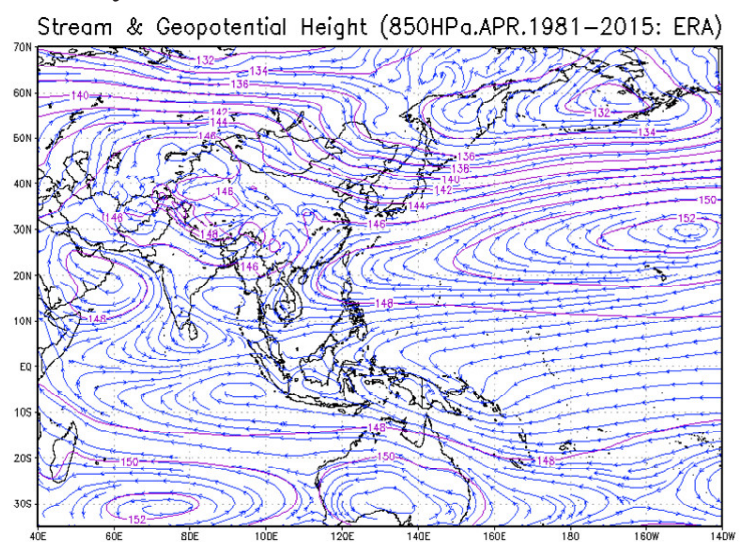

\subsection{Phương pháp nghiên cúu}

2.2.1 Phwơng pháp xác định ngày bắt đầu, ngày kết thúc $S M$

Để xác định ngày bắt đầu, kết thúc SM trên lãnh thổ Việt Nam, đồng thời loại bỏ được ảnh hưởng của đới gió tây nam xuất phát từ ACTBD đến khu vực, trước hết nghiên cứu sẽ phân tích đặc điểm trường hoàn lưu trung bình thời kỳ 1981-2015 trong thời kỳ đầu mùa hè (tháng 4 và 5 ).

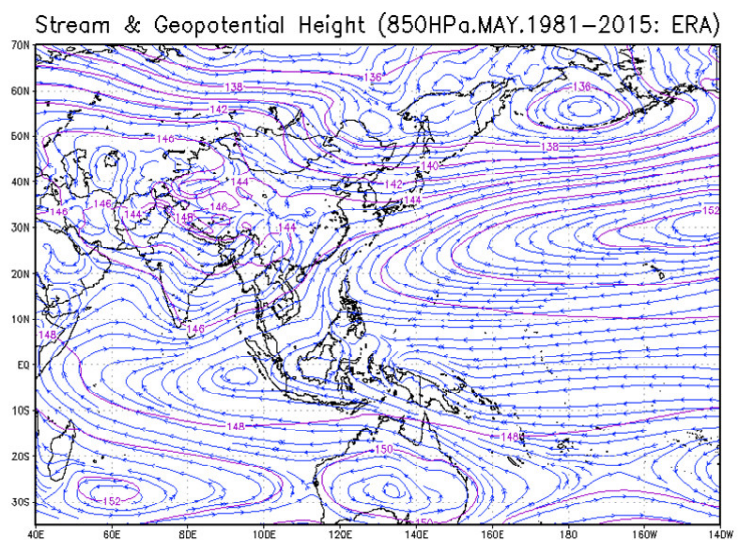

Hình 1. Truòng độ cao địa thế vị và đường dòng mưc 850hPa trung bình tháng 4 và 5

Có thể thấy, trong tháng 4, ở miền khí hậu phía Nam Việt Nam, gió đông, đông nam hay tây nam từ ACTBD gần như chi phối hoàn toàn. Trong khi ở miền khí hậu phía bắc, gió tây nam có nguồn gốc từ áp cao này, áp cao lạnh lục địa biến tính và áp cao ở bắc Ân Độ Dương chi phối. Tuy nhiên, điều này cũng không có nghĩa rằng, $\mathrm{SM}$ không có khả năng ảnh hưởng đến Việt Nam trong thời gian này, nhất là trong nửa cuối tháng 4 .

Sang tháng 5, đặc điểm hoàn lưu trên khu vực có sự thay đổi rõ rệt. Dòng gió từ ACTBD thu hẹp về phía đông và chi phối ở khoảng phía đông kinh tuyến $118^{\circ} \mathrm{E}$. Toàn bộ lãnh thổ Việt Nam lúc này đã nằm trong khu vực chịu ảnh hưởng của hệ thống gió từ dải áp cao Nam bán cầu. Chúng vượt xích đạo, đổi hướng, tràn qua Việt Nam rồi hội tụ vào áp thấp Trung Hoa. Ở các vùng khí hậu phía nam và Bắc Trung Bộ, gió có hướng tây nam còn ở Bắc Bộ gió có thiên hướng nam mạnh hơn.

Như vậy, có thể thấy, ở một khu vực nào đó, gió có thể có hướng tây hay tây nam nhưng lại không phải là gió tây nam của SM. Chính vì vậy, nghiên cứu này sẽ loại bỏ những hệ thống gió $\mathrm{SW}$ ảnh hưởng đến khu vực mà không bắt nguồn từ áp cao Mascarence và áp cao Châu Úc ở BCN.

Xác định ngày bắt đầu, kết thúc SM trên từng vùng khí hậu Việt Nam, nghiên cứu đã chỉ ra rằng, ngày bắt đầu, kết thúc $\mathrm{SM}$ trên các vùng khí hậu phía Bắc (Tây Bắc, Đông Bắc, Đồng

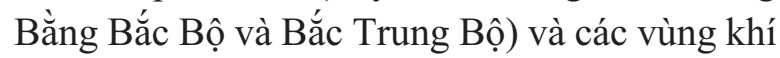
hậu phía Nam (Nam Trung Bộ, Tây Nguyên và Nam Bộ) cũng gần như trùng nhau, sự sớm (muộn) nếu có cũng chỉ 1 đến 2 ngày. Do vậy, bài viết này sẽ chỉ xác định ngày bắt đầu, kết thúc $\mathrm{SM}$ cho từng miền khí hậu phía Bắc và phía Nam Việt Nam.

Cụ thể, chỉ số gió vĩ hướng mực $850 \mathrm{hPa}$ trên các miền sẽ được xác định như sau: Trên miền khí hậu phía Bắc: U850_Bắc = U850 (16$\left.23,5^{\circ} \mathrm{N} ; 102-108,5^{\circ} \mathrm{E}\right)$; và trên miền khí hậu phía Nam: U850-Nam $=$ U850 $\left(8,5-15,5^{\circ} \mathrm{N} ; 103,5-\right.$ $\left.109,5^{\circ} \mathrm{E}\right)$. 
- Chỉ tiêu xác định ngày bắt đầu SM

Có thể thấy, ở các vùng khí hậu phía bắc, do gió mùa tây nam ảnh hưởng đến khu vực có thể có hướng nam hoặc đông nam nên chỉ tiêu về gió vĩ hướng sẽ không giống như các vùng khí hậu phía nam, nơi gió thịnh hành cơ bản là hướng tây suốt thời gian SM. Bởi vậy, chỉ tiêu xác định ngày bắt đầu của SM trên hai miền khí hậu cũng khác nhau (Bảng 1).

- Chỉ tiêu xác định SM bi gián đoạn

Đối với miền khí hậu phía Nam, một ngày có gián đoạn của hoàn lưu khi gió trên khu vực chuyển hướng đông hoặc vẫn có gió tây nhưng gió tây này từ $\mathrm{ACTBD}$. Sự xuất hiện gió tây từ ACTBD trên khu vực này được xác định nếu giá trị U850 trên vùng 5 (U5) có giá trị âm. Vùng 5 là vùng giới hạn trong khu vực $\left(100-115^{\circ} \mathrm{E}, 3-\right.$ $8^{\circ} \mathrm{N}$ ) (Hình 2).

Hơn nữa, trong 20 ngày tiếp sau ngày thỏa mãn tiêu chí ở bảng 1 , có ít hơn 5 ngày hoặc 3 ngày liên tiếp mà hoàn lưu trên khu vực bị gián đoạn.

Bảng 1. Tiêu chí xác định ngày bắt đầu SM trên các vùng khí hậu

\begin{tabular}{ccc}
\hline TT & Miền khí hậu & Tiêu chí \\
\hline 1 & Phía Bắc & U850_Bắc $\geq 0,5 \mathrm{~m} / \mathrm{s}$ và duy trì giá trị dương trong ít nhất 3 ngày liên tiếp, \\
2 & Phía Nam & U850_Nam $\geq 0,5 \mathrm{~m} / \mathrm{s}$ và duy trì giá trị dương trong ít nhất 5 ngày liên tiếp, \\
\hline
\end{tabular}

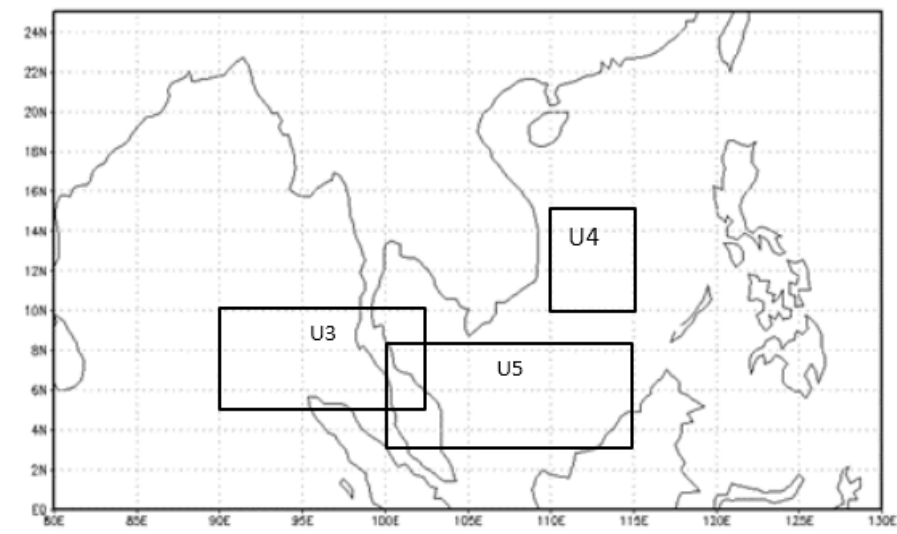

Hình 2. Các vùng để loại bỏ ảnh hưởng của ACTBD đến khu vực phía Bắc (U4) và khu vục phía Nam (U5), vùng xác định có sư mở rộng lên BCB của SM(U3)
Ở miền khí hậu phía Bắc, sự gián đoạn của SM trên khu vực được xác định khi U850 ở vùng 3 hoặc vùng 4 hoặc ở cả hai khu vực âm (U3 < 0 hoặc U4 $<0$ hoặc cả U3, U4 < 0). Chỉ tiêu này đưa ra để loại bỏ ảnh hưởng của $\mathrm{ACTBD}$ và các hệ thống khác gây nên gió tây trên khu vực.

- Xác định ngày kết thúc SM trên các vùng khí hậu

Ngày kết thúc SM được xác định tương tự như xác định ngày bắt đầu nhưng tiến trình thực hiện ngược về đầu năm.

Sự biến đổi của ngày bắt đầu, kết thúc và cường độ của gió mùa trong thời kỳ 1981-2015 được xác định dựa trên hệ số $\mathrm{a}_{1}$ từ phương trình hồi quy tuyến tính một biến.

\section{Kết quả và thảo luận 3.1. Đặc điểm chung}

Ngày bắt đầu, kết thúc SM trên các miền khí hậu trung bình trong thời kỳ 1981-2015 được chỉ ra trên bảng 2. Có thể thấy, ngày bắt đầu trung bình thời kỳ trên hai miền khí hậu xảy không có sự khác biệt nhiều, chỉ khác nhau một ngày (ngày $18 / 5$ và $19 / 5$ ) với độ lệch chuẩn khoảng 10 ngày (Bảng 2). Như vậy, SM bắt đầu muộn hơn khoảng 3-5 ngày so với kết quả của Ngô Thị Thanh Hương (2018) [2], khoảng 1 tuần so với kết quả của Nguyễn Đăng Mậu, 2018 [3] và tương đương với ngày bắt đầu SM trên khu vực biển Đông theo kết quả của Wang và cs (2004) [13]. 
BÀI BÁO KHOA HỌC

Bảng 1. Diện tích rù̀ng và đất ngập mặn các tỉnh ven biển Nam Trung Bộ năm 2018

\begin{tabular}{ccccccc}
\hline Miền khí & \multicolumn{2}{c}{ Ngày bắt đầu } & \multicolumn{2}{c}{ Ngày kết thúc } & \multicolumn{2}{c}{ Thời gian hoạt động } \\
\cline { 2 - 6 } hậu & TB & ĐLC (ngày) & TB & ĐLC (ngày) & TB (ngày) & ĐLC (ngày) \\
Phía Bắc & $19 / 5$ & 10,6 & $04 / 9$ & 9,6 & 107 & 14,0 \\
Phía Nam & $18 / 5$ & 11,4 & $26 / 9$ & 16,7 & 131 & 19,4 \\
\hline
\end{tabular}

Ngày kết thúc SM trên miền khí hậu phía Bắc sớm hơn miền khí hậu phía Nam 22 ngày với mức độ dao động ở vùng phía Nam lớn hơn vùng phía Bắc (Bảng 2). Thật vậy, ngày kết thúc SM trung bình trên miền khí hậu phía Bắc là ngày $04 / 9$, còn trên miền khí hậu phía Nam muộn hơn (ngày 26/9) và biến động cũng mạnh hơn. Sự khác biệt này càng cho thấy rằng, nếu dùng chung một chỉ số để xác định hoạt động của SM trên toàn lãnh thổ Việt Nam sẽ có nhiều bất cập. Sự bắt đầu sớm và kết thúc muộn hơn của $\mathrm{SM}$ trên miền khí hậu phía Nam làm thời gian hoạt động của nó kéo dài hơn 23 ngày so với miền khí hậu phía Bắc. Điều này một lần nữa khẳng định, tính hợp lý khi đưa ra các chỉ số khác nhau để xác định các đặc trưng gió mùa cho từng vùng, từng miền khí hậu.

\subsection{Biến đổi ngày bắt đầu, kết thúc gió mùa mùa hè}

Sự biến đổi ngày bắt đầu, kết thúc và thời gian hoạt động của SM qua các năm trong thời kỳ 1981-2015 được chỉ ra trên hình 2. Có thể thấy, có sự biến đổi tương đồng của ngày bắt đầu ở phía Bắc so với phía Nam. Trên cả hai miền, các năm $\mathrm{SM}$ bắt đầu sớm hay muộn thường xảy ra trong hoặc sau thời kỳ La Nina hay El Nino tương ứng. Cụ thể, trong các năm La Nina: 1996, 2000, 2001, 2008, 2012, SM trên cả hai miền đều bắt đầu trước ngày 10/5. Thậm chí, SM năm 2008 trên 2 miền còn bắt đầu vào ngày $3 / 5$ và $2 / 5$. Ngược lại, trong các năm E1 Nino: 1987, 1991, 1993, 2014 và 2015, SM trên 2 miền đều bắt đầu muộn vào khoảng đầu đến giữa tháng 6 , đặc biệt nó còn bắt đầu vào ngày 17/6 trong mùa hè năm 2015 (Hình 3).

Tương tự các nghiên cứu trước đó, ngày kết thúc SM trong các năm cũng có xu thế kết thúc sớm hơn trong các năm El Nino như trong các năm: 1983, 1992, 1993, 2007, 2014,...

Trong các năm này SM trên hai miền thường kết thúc vào khoảng giữa tháng 8 , thậm chí là ngày $31 / 7$ và ngày $9 / 8$ trong năm 2007 trên 2 miền khí hậu Bắc và Nam tương ứng. SM kết thúc muộn thường xảy ra vào khoảng sau ngày 20/9 (trên miền khí hậu phía Bắc) và sau ngày 15/10 (trên miền khí hậu phía Nam). Tuy nhiên, ngày SM kết thúc muộn lại xảy ra trong cả các năm El Nino $(2009,2015,1997)$ hay năm La Nina $(1999,2011)$ và năm không ENSO (2013) (Hình 3).

Hơn nữa, ngày bắt đầu $\mathrm{SM}$ có xu thế ngày càng sớm hơn khoảng 1 đến 2 ngày/thập kỷ. Ngược lại, SM trên miền khí hậu phía Nam có xu thế kết thúc muộn hơn khoảng 3,2 ngày/thập kỷ, trong khi đó, trên miền khí hậu phía Bắc thì không biến đổi nhiều (Hình 3).

Bởi vậy, thời gian hoạt động của $\mathrm{SM}$ cũng có xu thế tăng khoảng 5,7 ngày/thập kỷ (ở miền khí hậu phía Nam) và 1,27 ngày/thập kỷ (ở miền khí hậu phía Bắc) (Hình 3). 


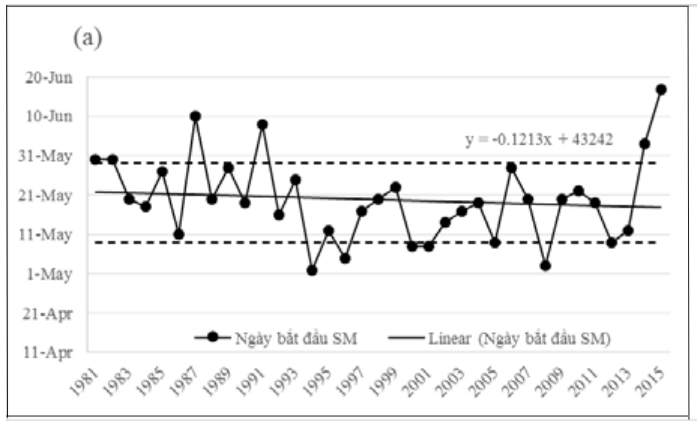

(c)
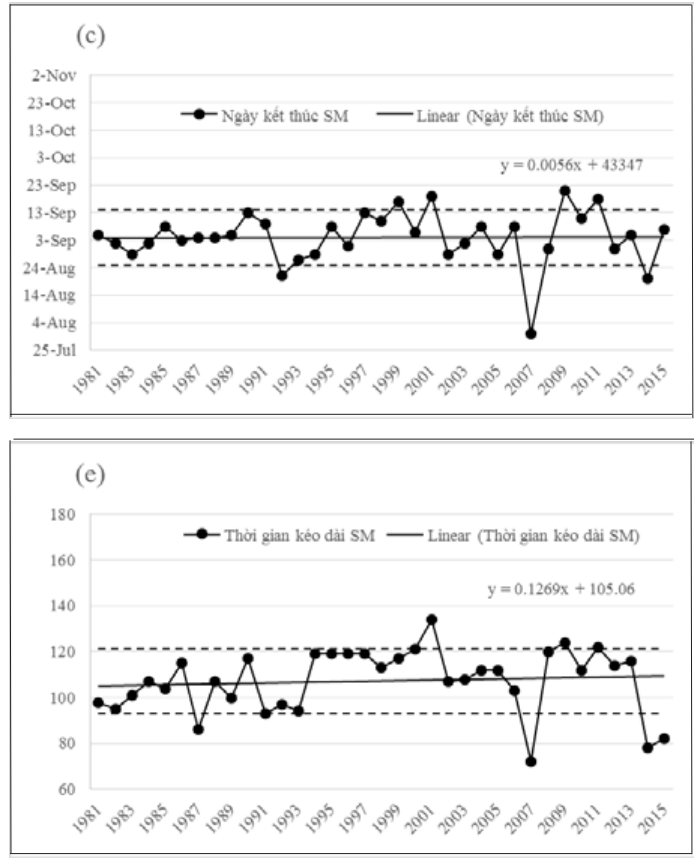

(b)

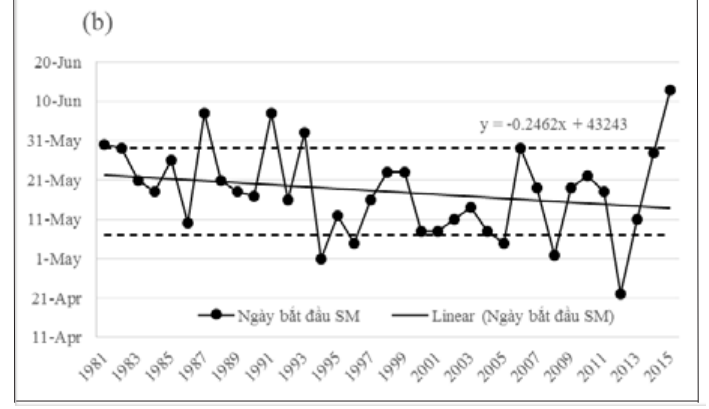

(d)
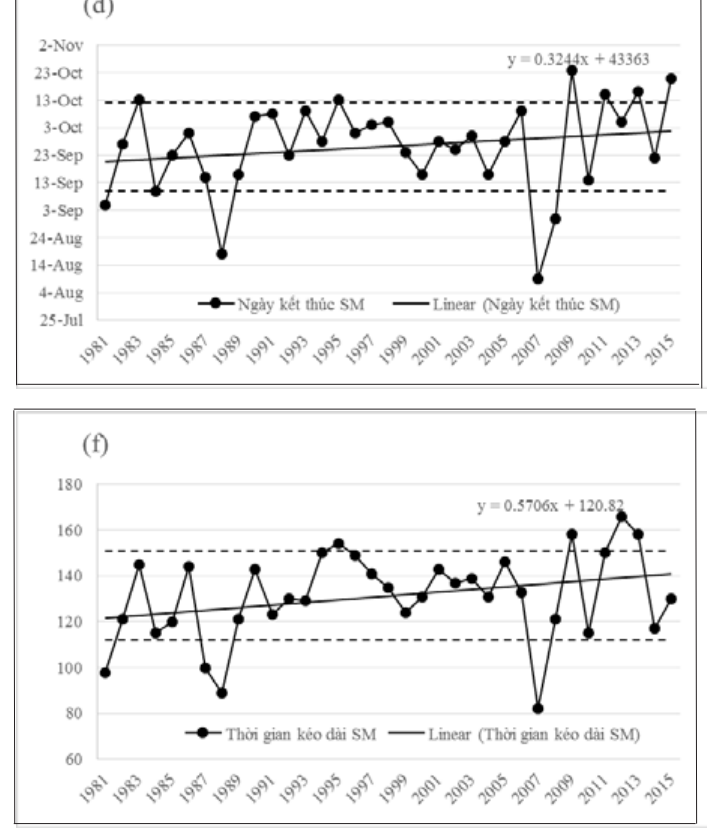

Hình 3. Biến đổi ngày bắt đầu $(a, b)$, kết thúc $(c, d)$ và thời gian hoạt động $(e, f)$ của SM trên miền khi hậu phía Bắc (trái) và phía Nam (phải). Trong đó, trên mối hình, hai đuờng đứt nét song song được xác định bằng giá trị trung bình thời kỳ 1981-2015 cộng (đưòng trên) hoặc trù đi (đuờng duơoi) độ lệch chuẩn của tùng đối tuợng tuơng ưng. Còn đường liền nét ở giữa biểu diễn xu thế biến đổi của tìng đối tương đó trong thời kỳ 1981-2015.

\subsection{Biến đổi cuờng độ gió mùa mùa hè}

Cường độ $\mathrm{SM}$ có sự biến động khá lớn qua các năm với giá trị độ lệch chuẩn tương đương khoảng $18,5 \%$ cường độ trung bình trên cả hai khu vực. Nhìn chung, trong thời kỳ 1981-2015, cường độ $\mathrm{SM}$ trên cả hai miền có xu thế biến đổi không nhiều. Song có thể thấy rất rõ, tốc độ gió vĩ hướng trung bình mực $850 \mathrm{hPa}$ (U850_Bắc) chỉ bằng khoảng $1 / 2$ U850_Nam. Điều này chứng tỏ, SM trên các vùng khí hậu phía Nam mạnh hơn trên các vùng khí hậu phía Bắc rất nhiều. Ở miền khí hậu phía Bắc, SM mạnh hơn trong các năm 1982, 1985, 1987, 1993, 1997, 2002 và 2012. Còn ở miền khí hậu phía Nam, SM lại mạnh hơn trong các năm 1982, 1985, 1990, 1994, 2009, 2011 và 2012. Tương tự, các năm SM yếu hơn ở miền khí hậu phía Bắc là các năm 1983, 1989, 1992, 2000, 2004, 2010 và 2013 còn ở miền khí hậu phía Nam là các năm 1983, 1988, 1995, 1996, 1998 và 2010 (Hình 4). Nhìn chung, sự mạnh lên hay yếu đi của $\mathrm{SM}$ trên từng miền xảy ra trong cả các năm ENSO và không ENSO, song trong các thời kỳ El Nino hoặc sau thời kỳ này, SM thường có cường độ yếu hơn. 

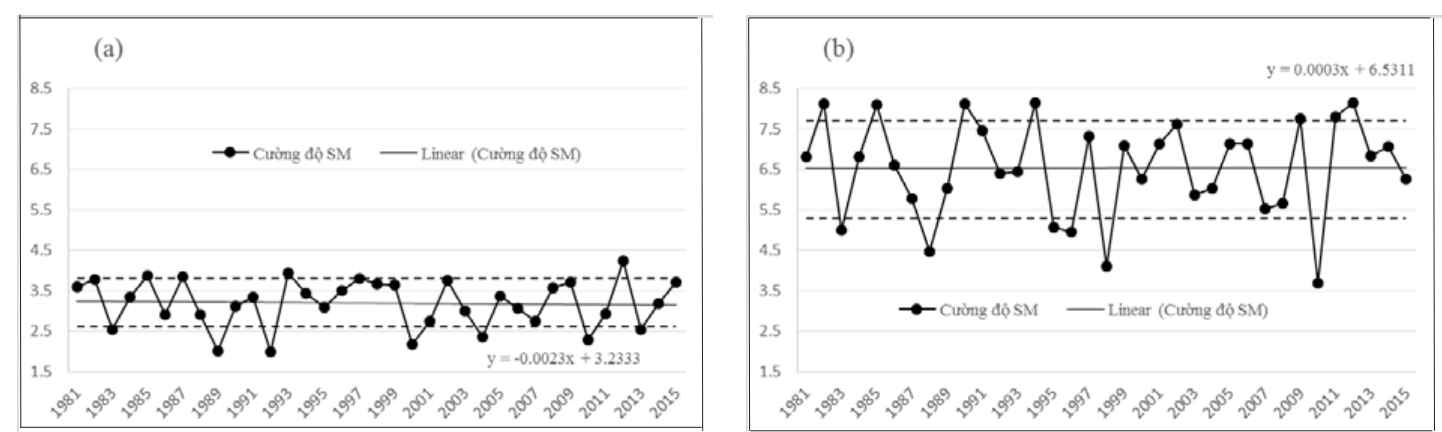

Hình 4. Biến đổi cuờng độ của SM trên miền khí hậu phía Bắc (a) và miền khi hậu phía Nam (b). Trong đó, hai đường đứt nét song song được xác định bằng giá trị trung bình của chỉ số SM trên tùng miền khi hậu cộng (đường trên) hoặc trù đi (đuờng duới) độ lệch chuẩn của chúng. Còn đường liền nét ở giữa biểu diễn xu thế biến đổi cuờng độ SM trên tùng miền

Những kết quả trên một lần nữa cho thấy rằng, các đặc trưng gió mùa trên các khu vực là khác nhau. Sự mạnh lên hay yếu đi của SM ở miền khí hậu phía Bắc không hoàn toàn giống với ở miền khí hậu phía Nam. Điều này có thể do sự khác biệt về đặc điểm địa hình cũng như ảnh hưởng của các hệ thống thời tiết khác nhau tác động. Tuy nhiên, vai trò của các hệ thống thời tiết hay các trung tâm khí áp đến hoạt động của SM sẽ được đề cập tới trong một bài viết khác.

\section{Kết luận}

Đặc điểm hoạt động của SM trên các miền khí hậu Việt Nam trong thời kỳ 1981-2015 đã được phân tích dựa trên sự biến đổi trong ngày bắt đầu, kết thúc, thời gian kéo dài và cường độ của chúng. Kết quả cho thấy rằng:

- SM trên miền khí hậu phía Nam thường bắt đầu sớm và kết thúc muộn hơn so với miền khí hậu phía Bắc.

- Trong các năm El Nino, SM thường bắt đầu muộn và kết thúc sớm hơn trong các năm $\mathrm{La}$ Nina.

- Trên cả hai miền, $\mathrm{SM}$ đều có xu thế đến sớm hơn khoảng 1 đến 2 ngày/thập kỷ.

- Ngày kết thúc SM trên miền khí hậu phía Nam thì có xu thế muộn hơn khoảng 3,2 ngày/thập kỷ, trên miền khí hậu phía Bắc thì biến đổi không nhiều.

- Thời gian hoạt động của SM có xu thế tăng khoảng 5,7 ngày/thập kỷ (ở miền khí hậu phía Nam) và 1,27 ngày/thập kỷ (ở miền khí hậu phía Bắc).

- Cường độ của SM trên các vùng khí hậu phía Nam mạnh hơn khoảng 2 lần so với các vùng khí hậu phía Bắc. Sự mạnh lên hay yếu đi của $\mathrm{SM}$ trên từng miền không bị chi phối nhiều bời hiện tượng ENSO, song trong các thời kỳ El Nino hoặc sau thời kỳ này, SM thường có cường độ yếu hơn.

\section{Tài liệu tham khảo}

1. Trần Quang Đức (2011), Xu thế biến động của một số đặc trung gió mùa mùa hè khu vưc Việt Nam. Tạp chí Khoa hoc ĐHQGHN, Khoa học Tự nhiên và Công nghệ, 27-3S, 14-20.

2. Ngô Thị Thanh Hương (2018), Biến đổi một số đặc trung gió mùa mùa hè ở Tây Nguyên và Nam Bộ. Luận án tiến sỹ Khí tượng và Khí hậu học.

3. Nguyễn Đăng Mậu (2018), Nghiên cưu đánh giá và dụ tính biến động của các đặc trung gió mùa mùa hè ở Việt Nam. Luận án tiến sỹ Khoa học Trái đất, Viện Khoa học Khí tượng Thủy văn và Biến đổi khí hậu.

4. Nguyễn Đức Ngữ, Nguyễn Trọng Hiệu (2004), Khi hậu và Tài nguyên Khi hậu Việt Nam. Nhà xuất bản Nông nghiệp. 
5. Nguyễn Thị Hiền Thuận (2005), Sụ biến động của các chỉ số gió mùa mùa hè ở Nam Bộ trong các pha ENSO. Tuyển tập báo cáo Hội thảo Khoa học lần thứ 9 , Viện Khí tượng Thủy văn.

6. Nguyen, L.D., Matsumotoa, J., Ngo, D.T., (2014), Climatological onset date of summer monsoon in Vietnam. International Journal of Climatology, 34, 3237-3250.

7. Fasulo, J., Webster, P., (2003), A hydrological definition of Indian monsoon onset and withdrawal. Journal of Climate, 17, 3200-3211.

8. Joseph, P.V., Eischeid, J.K., Pyle, R.J., (1994), Interannual variability of the onset of Indian summer monsoon and its association with atnospheric features, El Nino, and sea surface temperature anomalies. Journal of Climate, 7, 81-105.

9. Kajikawa, Y., Wang, B., (2012), Interdecadal change of the South China Sea summer monsoon onset. Journal of Climate, 27, 3207-3218, doi: 10.1175/JCLI-D-11-00207.1.

10. Liu, P., Qian, Y., Anning, H., (2009), Impacts of Land Surface and Sea Surface Temperatures on the Onset Date of the South China Sea Summer Monsoon. Advances in aTnospheric sciences, 26 (3), 493-502.

11. Pham, X., Fontaine, B., Philippon, N., (2010), Onset of the summer monsoon over the southern Vietnam and its predictability. Theor. Appl. Climatol. 99, 105-113. Doi: 10.1007/S00704-0090115-Z.

12. Prasad, V.S., Hayashi, T., (2005), Onset and withdrawal of Indian summer monsoon. Geophysical Research Letters 32, L20715, doi: 10.1029/2005GL023269.

13. Wang, B., Lin, H., Zhang, Y., Lu, M.M., (2004), Definition of South China Sea monsoon onset and Cemmencement of the East Asia summer monsoon. Journal of Climate, 17, 699-710.

14. Zhang, T.L., Wang, B., Wu, (2002), Onset of the Summer Monsoon over the Indochina Peninsula: Climatology and Interannual Variations. Journal of climate, 15, 3206-3221.

\title{
CHARACTERISTICS OF THE SUMMER MONSOON OVER VIETNAM \\ Chu Thi Thu Huong ${ }^{1}$, Tran Dinh Linh ${ }^{1}$ \\ ${ }^{1}$ Hanoi University of Natural Resources and Environment
}

\begin{abstract}
Abtracts: The characteristics of SM over Vietnam were analyzed based on the change in the start date, the end date, the duration and its intensity. From the reanalysis data set of the HGT and U fields at 1000hPa, 850hPa at 7 oclock daily and monthly averages in the period 1981-2015, SM indicators on the two climatic regions of Vietnam were determined. At the same time, SM indicators for each region are also launched to eliminate the southwest wind from the ACTBD. The results indicate that, SM in the southern climatic regions usually start early and end later than the northern climates. In El Nino years, SM usually starts late and ends earlier in La Nina years. In the period 1981-2015, in both regions, SM tended to arrive earlier about 1-2 days/decade. In contrast, the ending date of SM in the southern climate region tends to be later than about 3.2 days/decade, in the northern climate, the change is not much. Therefore, SM's operating time tends to increase by 5.7 days/decade (in the Southern climate) and 1.27 days/decade (in the Northern climate). Moreover, the intensity of SM in the southern climates is about 2 times stronger than in the northern climates.
\end{abstract}

Keywords: Summer monsoon, U850 index, Northern climatic region, Southern climatic region. 